\title{
University Records and Their Relation to General University Administration'
}

Messrs. Mood and Carstensen are members of the Department of History, University of Wisconsin.

$\mathrm{T}$ HIS PAPER will bring out some facts relating to the record management problems of three institutions of higher learning, and will offer some conclusions based on the facts. The paper rests on the experience of two men, and is a compounding of their reflections on that experience. ${ }^{2}$ It has had the benefit of the criticism of two recognized experts in the field, Helen Chatfield, record officer, Bureau of the Budget, Executive Office of the President, Washington, D.C., and Dr. Ernst Posner, professor of history and archival administration, American University.

The proposition is advanced at the outset that the instituting of an effective reference service to interpret university records is the ultimate aim of all university record activities. University records answer the questions of university administrators, who must solve current problems and plan for the future, and they provide materials for the

1 Paper presented at the University Libraries Section meeting, A.C.R.L., Chicago, Jan. 27, 1950 .

$2 \mathrm{Mr}$. Mood has used university records extensively for purposes of research in preparing a biography of Frederick Jackson Turner, and has examined university records in quantity while surveying those belonging to seven of the eight campuses of the University of CaliSeven of the eight campuses of the University of Cali-
fornia. He has also had administrative experience in record work during the war when he served as chief of Archives Section, Historical Division, HQ., AAF, Washington. Mr. Carstensen has supervised the sorting and arranging (1938.39) of the records of the Central Washington College of Education, founded in 1891 ; and has collaborated in the development of a detailed plan for the establishment of a permanent record office for the Quartermaster. Depot, Seattle. As a historian, he has worked first with the records of the University of Iowa for the period $1846-80$, and afterward with those of the University of Wisconsin, 1836-1925. university historians, who seek to peer into the university's past.

The plan of the paper provides for three brief case studies. Two of these cases will be drawn from the university field, and one from the liberal arts college field. This set of three case studies affords some contrasts in record problems, and some opportunities to indicate, even within so small a sample, the extensive scope and enormous variety to be found among bodies of university records.

The first case to be cited will be that of Beloit College, chartered in 1846 . The current records of such officers of the college as president, treasurer, business manager, the deans, superintendent of buildings and grounds, registrar, alumni secretary, etc., are maintained in the several offices. In some instances the noncurrent records also are kept in the offices. In others, however, the noncurrent records have been withdrawn and stored elsewhere. The records of the president's office have been subjected on occasion to the weeding process. Some of the older files of this office are now in basement storage, awaiting the weeding process. The faculty minutes of the college, kept in modern containers, are well protected. The trustees' records are abundant, though not absolutely full or complete. Their books of minutes are rounded out and completed by many packets and boxes of "exhibits" and other loose documents. Much of the older material that comes under the heading of "exhibits" and other similar documents pertaining to trustee action is kept in basement 
storage. The same repository also holds a good stock of noncurrent treasurer's records.

The principal, though not the sole repository for noncurrent records is in the basement vault in Middle College, the oldest building on the campus. This fire-resistant room measures 24 by 10 feet, and is eight feet high. Opening off the room is an iron door leading to a smaller vault, which also contains old papers. The possibility exists, of course, that dampness in the smaller vault may cause deterioration of the papers stored there. An evident danger in the larger chamber is the possibility of a break in a steam or water pipe. Under the direction of the business manager, work has already been begun in bringing the papers stored in these places into an orderly system.

In the basement of the college library is to be found an additional stock of record materials. Emeritus professor of history Robert Kimball Richardson has been the college archivist for some years. In his care he has certain pieces which originally formed part of the files of the offices of the presidency and of the treasurer. These record materials have marked interest in relation to the history of the college. Such papers, having been generated as a part of the administrative process, are true "records." The archivist has also in his charge such rich troves of manuscripts of historical interest, such as the Joseph Emerson correspondence, the Chapin correspondence, and the Emerson-Bannister correspondence. These groups of manuscript materials cover the period roughly from 1800 to 1920 , and possess high value for the history of the college and the Beloit area. In a strict sense, however, they are not administrative records. The college library also houses a collection of Beloitiana, including files of campus newspapers, college catalogs, publications by alumni, books and pamphlets relating to the history of the college, etc.

Officers of Beloit College are aware that they face record management problems. It is correct to say that they have already begun to take some steps. The valuable organizational work of Professor Richardson and of the business manager are cases in point. The logical sequel to these efforts would be to assign to a professionally trained record management officer the task of putting the total stock of college records in good order according to a well-coordinated and comprehensive scheme. Problems of retention and disposal could be settled by this expert, who would bring to this particular opportunity his professional insight and skill.

The case of a liberal arts college of this kind can now be discussed in general terms. Colleges of the sort do not as a rule possess sufficient stocks of records, or supplies of uncommitted funds to warrant the appointment of a full-time permanent expert, for when he has finished the basic work of organizing the records there is not enough left for him to do. It is possible that this diffculty could be overcome in several ways. A group of liberal arts colleges in the same region could club together and hire an expert between them who would visit each institution in turn, set its records in order and perform other archival functions, and then move on to the next institution in the contracting group. Or, one college could bring in an expert at an agreed-upon fee, who would undertake to accomplish the basic job within a stipulated time. He could undertake to return at stated intervals, in a supervisory capacity, to see that the system he had set up was working smoothly. It should of course be a part of the visiting expert's function to train some permanent member of the college staff in the proper maintenance and servicing of the records, once he has organized them. Indoctrination of this kind involves the establishment of appropriate procedures to make and keep the records as incorporated parts of the institution's assets.

Our second case study will be the Uni- 
versity of $W$ isconsin, chartered in 1848 . In this university we have a large institution with a century of growth and development behind it. Its stocks of records are correspondingly voluminous. It is not unlikely that Wisconsin's total record stock, if actually measured, would easily exceed a mile in length, and perhaps it would approach two miles.

A prominent characteristic of the records of a university is their amazing variety. The records of the $W$ isconsin regents contain the results of the deliberations of this important legislative and consultative body. The records of the faculties, academic and professional, are numerous, and so too are the records of faculty committees. The university counts some 60 to 70 departments and schools; each one of these has a file of records. Some of them are bulky. Administrative records are voluminous: witness the files of the registrar, the admissions office, and so on, offices which historically grow out of the faculty functions now turned over to full-time specialists. Administrative records that belong to the housekeeping category include the files of buildings and grounds, and business manager. There are files of course-directors' records, extension center records, veterans' affairs records, and records of the bureau of guidance and records. The radio station builds up files, and the student employment bureau, the student counseling center, the department of student health, the summer session office, and the office of loans and scholarships-all these and many others busily generate files.

But with the mention of this selection of offices and agencies which produce records in the course of instruction or administration, one has not come to an end. The university is a busy research center too, and the processes of investigation and research in their turn create copious stores of records. The content of these records is as various in subject matter as the projects that the investiga- tors choose to work upon. Research records in many instances have both a short-time value and a long-time value. A particular corpus of research records has worth, initially, for that one particular experiment. When the experiment, or a similar one, is repeated two decades later, the original mass of data finds renewed value for purposes of comparison, provided the data has been properly preserved. Examples of the almost permanent value of some kinds of research records in one or another scientific field could easily be multiplied.

The current records of the university are kept in their several offices of origin. For the noncurrent records there is at the present time no central depository. Such an installation is badly needed. In its absence the valuable older records of the university lie scattered about here and there. Some old ones have disappeared. Some had disappeared but happily were found again : an instance is the early reports to the board of regents. Some have been damaged beyond hope of repair : an instance is the file of old letter books of the presidency during the latter part of the Chamberlin and the earlier part of the Adams administrations. The neglected and scattered conditions of the university records became evident in 1944 at the time when work was begun on the centennial history of the University of Wisconsin. It was then seen that though it was too late to repair all the damage due to past neglect, it was time to set to work and try to save what was left of the early records, and to look out for the preservation of present oncoming records. The conclusion was reached that the university needed an archival depository, and an archival officer. This conclusion was brought to the attention of the university administration toward the end of 1945 by Messrs. Curti and Carstensen, co-authors of the university history, then in progress. They urged that the important bodies of records be systematically 
collected, properly housed, and preserved. ${ }^{3}$

Thus as a consequence of delving among the university's records in search of source material for a university history, it became apparent that the university needed to establish an archives as part of a total record management program. It was thoughtlessly carrying into the future generous large amounts of useless paper, housed in valuable space, requiring filing equipment of varying degrees of expensiveness. It was closing its eyes to the costly deployment or scattered condition of its records. It was but little aware of the loss of some of its papers, and the dangers menacing others. Representations having been made, the university administration took cognizance of the existing situation by the appointment of a committee charged with the duty of looking further into the facts, and hope for positive developments in the future can be entertained.

The primary consideration that sanctions the preservation and safekeeping of research records is their future utility for research purposes. The primary consideration that sanctions the preservation of administrative documents is that they make possible the transaction, or the easier transaction, of future business. Take a sample. Old check registers, old checkbook stubs, establish the date when a given person came to work for the institution. Date of commencement of work becomes important years afterward in relation to pension and retirement schemes. Where no records exist, memories can and do differ. Where official documentation is extant, correspondence or conversations need not be prolonged. Thus the utility of university records is their utility for the continuing or the unexpected purposes of administration. Their usefulness in this respect is limited only by the imaginations of those who see fit to consult them. The preserva-

3 Curti, Merle, and Carstensen, Vernon. The University of Wisconsin, $A$ History, $1848-1925.2 \mathrm{v}$. Madison, 1949. For mention of record and archival materials used in the preparation of this history, see the bibliographical note in v. 2, p. 597-60r. tion of records for the special purposes of historians, although very important, is a secondary consideration. But the case for establishing university archives does not rest originally upon the fact that such depots are pleasing to the historically minded.

Our third case study is the University of California, chartered in 1868 . The Berkeley campus is the institution's point of origin. Now the system includes seven other campuses, with a large faculty and a student body of more than 40,000 , governed by a single board of regents. It was to be expected that an institution of this size would have developed some record management problems. In December I945 Mr. Mood proposed to the administration of the university that a survey be made of the accumulated records and archives built up over the years. The administration adopted the suggestion in the summer of 1947 and the survey work began about October I5. Between that date and the end of June I 948 the seven outlying campuses were visited, their records viewed, and their record and archival problems canvassed. The search led upstairs and down, into basements and subbasements and heat tunnels, into corners and closets and dusty attics, into offices and still more offices. There were records on top of a coast range peak, Mount Hamilton; near the edge of the desert, Riverside ; at sea level, La Jolla; in a metropolis, Los Angeles; and on a farm, Davis. This is not an exhaustive list of places visited. As far as possible current and noncurrent records viewed were measured with a metal tape carried for the purpose, and the figures recorded on the spot. The procedure thus created another record during the process. Counting card-size and folder-size records as one must, it appeared when the totals were in hand that the minimal values for university record holdings on seven campuses were a little more than five and one-half linear miles. Add the hidden, lost, and temporarily forgotten records, and 
others overlooked for whatever reason, and one realizes that the true values will be even greater.

The variety of records viewed was considerable: records on paper, film, glass; flat and rolled records; photographic records; records turned out by automatic recording machines of one kind or another; maps, charts, statistical tables; logbooks; drawings, architectural, engineering, and zoological ; files of printed forms filled in with data; reports and memoranda; letter books; files of correspondence; notebooks of several kinds : laboratory notes, field notes, and even steam and water pressure records.

It thus became abundantly clear that the University of California was copiously supplied with records. By the time the seven campuses had been visited, it seemed obvious that a survey of the records at Berkeley was not necessary since this was the oldest and largest campus. Casual visiting in this or that office on the Berkeley campus revealed serried ranks of filing cases filled with current records. It could be left for the imagination to conjecture where the noncurrent records were.

The presence of these masses of record material had been creating by degrees entire families of record management problems. Some of these may be referred to in passing: problems of filing and arranging; problems of equipment, space, storage, fire hazard; problems of retention and disposal. Many university employees were giving thought to problems arising from the bulk of the records in their charge. It became clear as the survey went on that already there were taking place many spontaneous, groping, and uncoordinated movements, designed to relieve the record management problem of this or that particular office. The pressures of practical situations were acute almost everywhere.

The survey raised two leading questions: (I) was the university ready to recognize the existence of its record problems? (2) If so, was it prepared to take appropriate action in relation thereto? The issue is, does it choose to act or to drift along, recognizing all the risks, costs, and inconveniences that such drifting entails?

It is clear that the accumulation of masses of such records over the years produces many record management problems. To deal with such problems in an orderly way is the province of specialists in the field of archival administration and record management. Such specialists have behind them a fund of theory and a body of experience that can be applied to the varied and differing situations that are met with in the course of their professional work. These experts have already proved their worth in government and in business. Business organizations have assimilated and applied record management programs for the sound reason that they could not function today without such procedures. The Metropolitan Life Insurance Company of New York has on file $144,000,000$ individual policies, and can produce a needed one almost instantaneously. Its presently retained records extend to I 7 miles, and its record management service has the entire mass under precise and smoothly functioning control. Business is ahead of the universities in caring for its records, not because business has lately been converted to the idea of business history, but because "Recorded experience is a corporate asset-as much of a corporate asset as plant, equipment, and inventory."

How shall a university administration act when it reaches the point of readiness to do something positive about its record and archival problems? It can appoint an archivist or record management officer who will draw up long-term plans. Or, alternatively, it can approve the making of a survey of its records, and thereafter decide on its course of long-term action. The latter was the line taken by the University of California. How- 
ever, now that a survey and an investigation of such extensive character has been carried out for California, it is open to question whether other institutions need to go to the like expense. It can safely be predicted, on the basis of the California study, that university records will be large in bulk and varied in character. Also, rough ideas of the volume of the current and noncurrent records on hand can be obtained from the officers of a given institution by applying to them in the usual ways. Such approximations will sufficiently serve, at least in some cases, at the outset. However, it is here stressed that a survey does give more precision and more definiteness than the other prodromal approaches can yield. Intermediate level administrators with acute record problems cannot always make their wants known to the top-level administrators. In such cases there is a chance for a survey to have influence by confirming independently the self-evident facts for those who have eyes but see not, and by dazzling them by the magnitude of the final statistical total.

The alternate opening move for a university that wants to act on its record problems is to set up a university archivist's office and staff it with a trained, experienced specialist. At the same time the administration should plan to bring into being a committee of wellselected university persons to consult with the archivist concerning the evaluation of the records to be disposed of or retained. The appointment of an archivist ought to mean that the "practical" work on the campus will begin soon after his arrival.

The first step to be taken by the new archivist should be the preparation of a quantity of retention and disposal schedules. These should be made out in cooperation with the heads of the several offices in the university, and should cover records now held, noncurrent and current, and records of similar types to be created in the future. It is the characteristic and specific objective of disposal schedules (as against simple lists) that they make possible the destruction or elimination not only of records alreay on hand, but also of similar records to be created in the future. Schedules constitute inventories and appraisals of given records. In detail they outline methods of storage, the time needed to keep the current records in the originating office, and in the depository space; also, the agreed-upon date of destruction. Scheduling is a procedure that is performed in relation to a specific form of record. Ideally, the schedule is worked out after the life history of the specific record has been ascertained. It should be prepared in the light of careful consultations had with all interested parties.

The second step is for the university archivist to submit the schedules thus prepared to his consultative committee. The composition of a committee of the kind should be carefully attended to. Its membership ought to represent different interests. A law officer of the university should be on the list. An experienced man of university business should be on, too. The trustees or regents should be represented directly or otherwise. The registrar is another likely candidate for inclusion. A member of the faculty, if put on, might well be a historian. Other functionaries could of course be added to acquire a broad base in experience. The archivist himself acts as secretary of this committee. A broadly based committee should be able to consider wisely and to act prudently upon the schedules submitted to them. It should be in a position to judge of the legal, educational, administrative, and historical values inherent in given bodies of records when the schedules come up for consideration.

The effects of the scheduling process, when carried out over a period of years, would be to improve matters on an encumbered campus. Noncurrent records would be retained while they had utility, and no longer. These noncurrent records, once 
they were properly organized, would be available for reference use as needed. The initial mass of unneeded papers having been disposed of, and a clear notion of the quantity of existing retained records then being known, as well as the bulk of the annual new increment of these, the subject of a suitable archival depository could then be taken up. Preliminary needed space would be forthcoming in the various existing storage places, as various specific disposal programs cleared out bodies of records here and there.

With the "practical work" well under way, the archivist could sooner or later undertake consultative work with the custodians of current records in the several university offices, suggesting various savings and economies in practice and procedure. It is a fact that economies in current record management tend to move forward and cut down expenses later on when current records become noncurrent records. Various useful suggestions concerning the filing schemes and procedures to be employed can be offered by record management specialists and by archivists. They have found waiting markets for this kind of information and are interested in providing it because they are presently concerned with the other fellows' records which they may one day be required to preserve and house, as their own.

From the record management officer, busy with his "practical work," let us now turn momentarily to glance at the office this individual heads. We will here set forth in brief style the essential functions of a modern record office. Such an office should of course be a clearing house for the consideration of problems of the sort we have been talking about. These are its essential functions :

(I) Accessioning of noncurrent records of continuing or enduring value.

(2) Maintenance and rehabilitation.

(3) Arrangement and description of accessioned records.
(4) Provision of reference service on accessioned records.

(5) Photographic reproduction of records.

(6) Advisory service in connection with active records.

(7) Disposal of useless noncurrent records.

This list of functions is taken from the Report of the Advisory Committee on New York State's Record System, Albany, 1948, p. 5-7. A university archivist and record management officer, fulfilling these functions, could, by working cooperatively with other university officers, gradually clear out unneeded record stocks, reduce "crisis" situations, provide schedules for submission to his consultative committee, and give a tonic sense of direction for all other relevant record management services. However, it should be remembered that just as time was passing while the acute situations were coming into being, so time must elapse before the inflammations in the body academic can subside after rational treatment has once begun.

The archivist or record management officer in a university should be trained and be experienced in the theory and practice of his special discipline. The data with which he works are records and he should know records, their utilities, and what has been learned about the problems they pose for university administrators. These administrators must depend on information for the transaction of their business, whether it be policy formulation, decision making, or oversight of routine administrative operations. Within the university an administrator has available two chief sources of information (whether organized or not), the library and the stocks of records.

The university library consists of a collection of published material which (for the most part) has been produced extramurally, and has been selected from many sources far 
and near to meet the specific needs of a given campus for information concerning the world in general and in particular. The university records, by contrast, have been created intramurally. They are unpublished papers, etc., organically structured accumulations of closely interrelated materials that reflect the specific activities and specific functions of a particular university. They document the experience of the university in all its factual details. The stock of records of a university is unique, and is noninterchangeable with the stock of another university. The permanent and essential core of the records, known as the archives, has a value that endures beyond its current value for the administrators of the day. This essential core, which is added to over the years, is handed down to the future as indispensable research material.

The special character of record materials has led and is leading to the development of special techniques for the surveying of university records, their management, arrangement, classification, and indexing. Such techniques differ radically from library techniques because of the very nature of the record materials themselves.

From functions of an archival agency and the special qualities of the materials it administers we move on to consider an administrative problem.

Where shall the university archivist be niched in the university hierarchy? Where, as an agency of university administration, shall the archives be placed? Much depends upon the answers to be given to these queries.

We are of course aware that in some institutions the archives have been established as a unit inside the university library system, with the archivist directly responsible to the librarian. This is the case in Harvard University. The Harvard instance is historically well rooted, ${ }^{4}$ but is not providing the

\footnotetext{
4 See the two thoroughly informative articles by $\mathrm{Dr}$. Clifford K. Shipton, "The Harvard University Archives:
}

model which universities now setting up record agencies tend to follow today. ${ }^{5}$

Harvard and some other institutions, then, have had their records carqd for by librarians, or by persons on the staffs of libraries. The point has already been made, however, that books and records differ radically as to their origin and nature and thus the handling of record material calls for the application of principles that have been derived from their very nature qua records or archives.

We are grateful for what the librarians have done to realize the historical significance of college and university records, to provide for the safekeeping of important parts of them, and to make them available for research in college and university history. We owe it to their vision that the need for a university archives as an integral part of these institutions has been recognized in many places. Let us bear in mind, however, that these pioneers in the university record field took action at a time when university records were thought of exclusively in terms of their research value; when universities and colleges were elementary and small institutions when compared with their present

Goal and Function." Harvard Library Bulletin, I : IoI08, Winter 1947; and "The Collections of the Harvard University Archives." Ibid., I : I 76-84, Spring 1947.

Under date of July I 2, I 948 , Mr. Shipton, the head of the Harvard Archives, wrote Mr. Mood: "Of the universities which have set up archives departments after versities which have set up archives departments after
studying our organization here, only one, I think, has followed our plan of having the department a division of the library. There are certain obvious reasons against our practice. An archive is not a library; its functions and materials are quite different. With us, the office of archivist has been united with that of librarian since the days of Jared Sparks. Some of the [Harvard] librarians, like Lane and Potter, have been more interested in the archives than in the larger problem of the university hbraries. When I took over ten years aru, the archives department was too small and its function too limited to make it a separate department under the Corporation.

"Unly today, however, we have becn going over the fact that within a year or so the archives departmen and the other service departments of the library will have to be separated from the teaching functions of the library and be carried on a special budget. Perhaps we shall be grouped for budget purposes with the Publication Office and Alumni Records Office which have recently been brought into the Widener Building.

"In universities in which the archives department is "In universities in which the archives department is a part of the library, the actual archival material in the of material. Here the material about Harvard is much more voluminous and in much more constant use than such material is in a younger institution." 
complexity and magnitude; and when the record problems of institutions of higher learning had not yet assumed their present large proportions. The problem today is no longer one of mere preservation of permanently valuable material. Indeed, there is not one but a plurality of problems. Their solution depends upon a total attack upon the total university record problem. This attack requires the training and the skills of the record manager (archivist). Is this probably not a labor which the librarian will be loath to take upon himself? It is indeed a task which the librarian will be willing to leave to the professionally trained expert. The record management expert, needless to say, will cheerfully and with gratitude recognize what it is that the librarians have already done in clearing the ground for the solution of the bigger problems that lie ahead. ${ }^{6}$

Given the nature of university archives and record problems, then, it should be clear that the record manager (archivist) must be assigned a position in the university hierarchy that will enable him to tackle his job with success. To carry on his work effectively, this officer must be located close to the center of university administrative authority. In most institutions today this means that he must be close to the president. The record officer requires the prestige and the influence that flow from an intimate relation to the presidential office, if he is to get on with his work. ${ }^{7}$ And it is only from the vantage point of top-level university

${ }^{6}$ Librarians are sure to be interested in the article by John Melville Jennings, librarian, Virginia Historical Society, Richmond: "Archival Activity in Amercan Universities and Colleges." The American Archivist,

I2: I 55-63, April 1949. stituted an archival unit. The plan under which the agency will operate is well discussed by the Rev. Dr. Henry. J. Browne, archivist, in an article, "A Plan of Organization for a University Archives." The American Archivist, I 2:355-58, October 1949. The article publishes the text of "Regulations for the Department of Archives and Manuscripts," necessary reading for all who follow developments in this growing field. Attention is called particularly to regulation number 2 : "The De- management that the record officer will be able to see and to understand the total complex of record problems of his institution. Once he has gained this understanding, he can proceed to draft a suitable record policy for his university, and can set at once to carry it out in an effective fashion.

It is obvious that the job of the university archivist is not limited to the care and custody of noncurrent records, and it is probable that he should be designated as record officer (archivist) rather than as archivist of the university. His should be the duties also of assisting in the installation of an all-university record program, in training of responsible staff members, and in the working out and implementing of a disposition program that makes possible the periodic retirement of noncurrent records and the transfer of the permanently valuable material to the university archives. It is in this way that he can render an extremely valuable, financially profitable service to his institution.

We believe that the general principles we have stated offer the best opportunity for future growth that will be constructive. At this interesting moment in the unfoldment of university record programs we recommend to university librarians that they encourage university administrations to adopt an informed attitude toward the related though distinct specialty of archives and record administration. ${ }^{\mathrm{s}}$

partment will be a separate unit of the University under the immediate jurisdiction of the Rector and it will have a separate budget which will be submitted annually to the administration."

8 After the paper had been typed, it was handed to Dr. Louis Kaplan, associate librarian, University of Wisconsin. His comment is given below:

"An archivist on the staff of a library, working under presidential directive, should have sufficient powers to proceed without handicap. The relationship of university records to the ordinary 'archival' materials found in libraries is a close one; and the library may be the only building with sufficient storage space for records. To place the record officer on the staff of the president, with working quarters in the library, would president, with working quarters in the library, would
always present difficulties. On the ideal situation, I agree with the authors of this paper, namely, that there be a record officer on the staff of the president, with the records stored outside the library. In such circumstances, the usual memorabilia and 'archival' materials found in libraries should eventually be trans. ferred to the record officer." 